\title{
Paleohealth based on dental pathology and cribra orbitalia from the ancient Egyptian settlement of Qau
}

\author{
Hisashi FuJITA ${ }^{1 *}$, Hiroto ADACHI ${ }^{2}$ \\ ${ }^{1}$ Department of Bioanthropology, Niigata College of Nursing, Joetsu 943-0147, Japan \\ ${ }^{2}$ Department of Psychiatric Nursing, Niigata College of Nursing, Joetsu 943-0147, Japan \\ Received 28 July 2016; accepted 14 March 2017
}

\begin{abstract}
Reports on the health of the people of ancient Egypt, one of the four great civilizations of the world, are of considerable interest to many. This paper addresses the paleohealth of people from Qau in ancient Egypt based on samples housed at the University of Cambridge. This skeletal series extends from the Protodynastic Period to the 30th Dynasty, with the largest number being from the 6th to 8th Dynasties. The remains are divided into four groups (male, female, early middle age, and late middle age) and physical anthropology methods were used to investigate dental caries, periodontal disease, antemortem tooth loss, dental wear, alveolar bone recession, enamel hypoplasia, and cribra orbitalia. The study was limited in that resource materials from multiple dynasties were combined, and no postcranial skeletal examinations were possible. However, the following matters were found regarding the paleohealth of the ancient Egyptian Qau people: (i) the rate of dental caries was low; (ii) periodontal disease was present and progressed with age; (iii) even so, tooth loss was low; (iv) dental wear was pronounced; and (v) there were no age-related stress markers, and few individuals with serious disease. Overall, based on the Qau people in this data, it can be assumed that the health status was poor, the death rate of newborns, infants, and young children was high, and individuals exhibiting severe stress markers died before reaching adulthood. Ancient Egyptians have long been the subject of much anthropological and archaeological study, and this paper introduces several interesting topics for further investigation concerning the paleoenvironment and paleohealth of these ancient people.
\end{abstract}

Key words: paleopathology, ancient Egypt, Qau site, stress markers, paleohealth

\section{Introduction}

Egypt is a region of great anthropological interest because mummies and ancient human remains have been discovered at a number of archaeological sites. In the area of dental paleopathology, some pioneering and excellent papers by Leek have been published (Leek, 1966, 1967, 1972a, b, 1973). Gerloni et al. (2009) have reported that X-ray analysis of mummies revealed severe dental wear and periodontitis. Forshaw $(2009 a, b)$ noted that X-ray analysis has revealed that many ancient Egyptians suffered from painful dental conditions, and found numerous dental abscesses. Melcher et al. (1997) have also pointed out that X-ray analysis reveals multiple instances of severe dental wear, caries, and periodontitis. Based on the frequency of enamel hypoplasia, Starling and Stock (2007) have proposed that the nutritional state of people in the Nile valley improved with the introduction of agriculture. Keita and Boyce (2001) also investigated enamel hypoplasia in ancient Egyptians exca-

* Correspondence to: Hisashi Fujita, Department of Bioanthropology, Niigata College of Nursing, 240 Shinnan, Joetsu 943-0147, Japan.

E-mail: hfujita@niigata-cn.ac.jp

Published online 6 April 2017

in J-STAGE (www.jstage.jst.go.jp) DOI: 10.1537/ase.170314 vated from the Naqada region, and indicated that such a marker correlates with increased population density and social complexity; hence enamel hypoplasia could be interpreted as sign of population stress.

These previous studies have provided an abundance of valuable information. In most, however, the number of individuals is not particularly large, and differences in sex and age are not taken into consideration. The first author has recently investigated dental disease in archaeological human remains from various African countries that are housed at the University of Cambridge, UK, where he is currently a visiting fellow. Archaeological human remains from excavations at the Qau site of ancient Egypt were grouped by sex and age, and this paper discusses the frequencies of antemortem tooth loss (AMTL), alveolar recession, caries, location of caries, dental wear, linear enamel hypoplasia (LEH), and cribra orbitalia (CO). The present study aims to provide an overview of dental disease and the stress marker $\mathrm{CO}$ in ancient Egyptians from the Qau excavations, and by discussing differences in sex and age, elucidate the health status of people of that time in greater detail.

\section{Materials and Methods}

The samples analyzed in this study were excavated human 


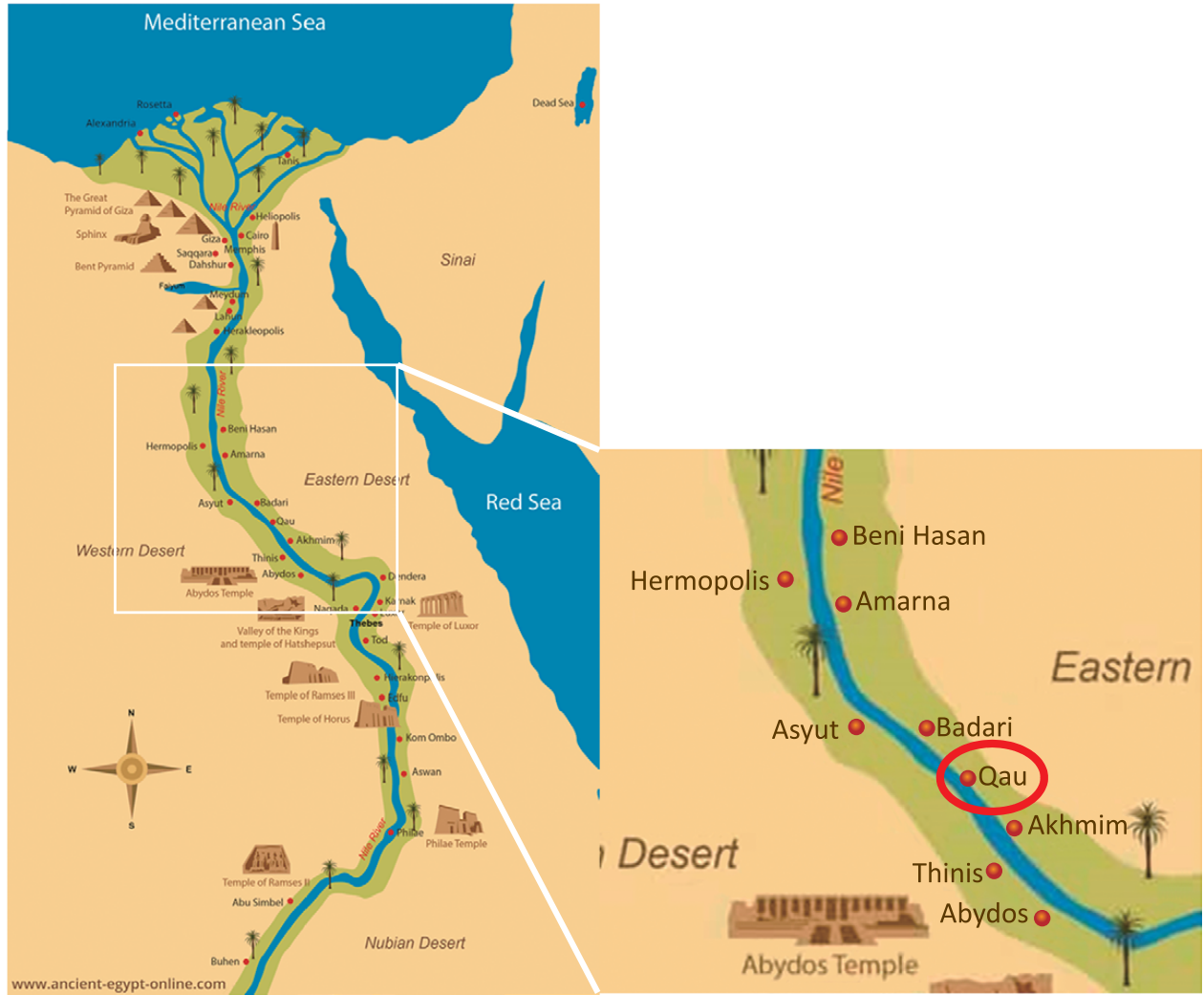

Figure 1. The location of Qau, ancient Egypt.

skeletal remains that were obtained from the ancient Egyptian site of Qau and have been housed at the University of Cambridge since 1941. Qau is the Arabic name of an upper Egyptian village located on the east bank of the Nile (http:// www.ucl.ac.uk/museums-static/digitalegypt/Welcome. $\mathrm{html}$ ), about $5 \mathrm{~km}$ east of the village and train station Tima, and $45 \mathrm{~km}$ south of Asyut. Qau is located by the site known in ancient Greek records as Antaeopolis, i.e. 'city of Antaeus.' Ptolemy IV built a temple there, substantial parts of which were still standing at the beginning of the 19th century, when they were used to build a palace at Asyut (Figure 1). Even at the laboratory of the University of Cambridge, no further information is available regarding these samples.

The materials used in this study ultimately involve 144 individuals. Infants and elderly individuals were excluded because they were present only in very small numbers. These 144 individuals consist of 42 males and 63 females in early middle age, and 21 males and 18 females of late middle age. Among these, material for which only the mandible remains comprises 3 males in early middle age, 3 males of late middle age, 7 females in early middle age, and 4 females of late middle age. The individuals with only maxilla remaining consist of 1 male and 3 females in early middle age and 1 female of late middle age. The ages of the individuals were estimated using the degree of cranial suture closure as the main index (Meindl and Lovejoy, 1985) and degree of dental wear (Fujita, 1993), and the individuals were divided into two major age groups: early middle-aged and late middleaged groups. Early middle age was established to be approx- imately 20-39 years old and late middle age was 40-49 years old. The sex of the individuals was determined from the size of the mastoid process, the development of the brow ridge, the condition of the occipital protuberance, and the overall skull size and robustness of the cranium. Alveolar bone loss was measured using the distance from the cemento-enamel junction (CEJ) of the maxillary or mandibular first molar to the respective alveolar crest (Figure 2). Tooth loss was established as antemortem tooth loss (AMTL) if the alveolar socket was closed or in the process of closing. Postmortem tooth loss was identified if the alve-

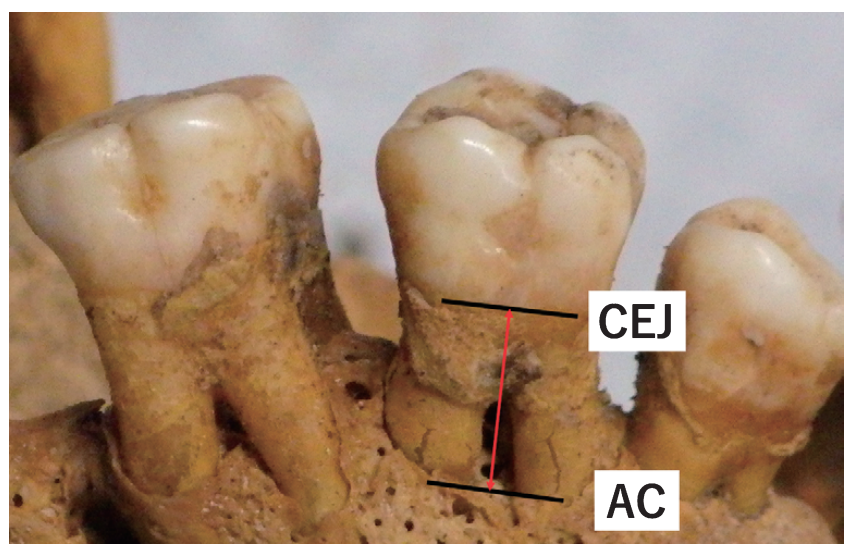

Figure 2. The measurement of alveolar bone distance. CEJ, cemento-enamel junction; AC, alveolar crest. 
olar socket was completely open. Carious lesions were classified as C1, C2, C3, or C4 (Matsumoto, 1995). The classification of Fujita (2009) was used for caries sites (Fujita 1994, 2009). Because of the small number of samples, caries was judged as either present or absent, and carious sites were divided into two groups, including coronal caries and root caries. LEH was classified using the three grading levels of Yamamoto (1989). However, the grading levels were pooled because the number of samples was not so large. The dental wear level was classified using eight grading levels based on the method of Fujita (1993). CO was classified using four grading levels: no $\mathrm{CO}$, porotic type, cribrotic type, and trabecular type (Nathan and Hass, 1966). However, the grades were also pooled because the number of samples was not so large.

A chi-square test was used to compare the AMTL rates, prevalence of dental caries, enamel hypoplasias, and incidence of CO by age and sex. The Mann-Whitney $U$-test was used to compare dental wear by age and sex, and Student's $t$-test was used to compare alveolar loss by age and sex.

\section{Results}

Table 1 shows the state of ATML in skeletons excavated at Qau and the results of tests for significant differences in tooth loss between male and female, and between early middle age and late middle age. An examination of tooth type revealed that although some tooth types did not show a significant difference, tooth loss in both male and female was statistically greater in late middle age than in early middle age, and the ATML score increased with age. Table 2 shows the degree of dental wear for early and late middle-aged males and females, and the results of tests for significant difference. Although some tooth types did not show a significant difference, the degree of dental wear on the other many tooth types progressed with age. Table 3 shows the results for the degree of alveolar recession and the results of tests for significant difference. In males, no significant differences in the degree of alveolar recession by tooth type were found between early and late middle age (upper first molars in both sides), but in females the degree of alveolar recession in all tooth types was greater in late middle age. In both males and females, alveolar recession was at the $5 \%$ and the $0.1 \%$ significance level in late middle age, and was greater than in early middle age. Table 4 shows the rate of dental caries. In males, the rate of caries in all tooth types showed no significant difference between early and late middle age. In females, however, the rate of caries in late middle age was lower than in early middle age, and was high at the $5 \%$ significant level in early middle age. Table 5 shows the locations of caries. Excepting late middle-aged females, root caries predominantly exceeded coronal caries, and when the locations of all caries in the Qau remains were combined, root caries exceeded coronal caries at the $0.1 \%$ significance level. Table 6 shows the LEH results. LEH was found in 34 of 108 individuals $(31.48 \%)$ who were examined. No significant differences whatsoever were found, however, between males and females and in age-related changes. Among the excavated Qau remains, $\mathrm{CO}$ was found in 21 of the 124 individuals $(16.94 \%)$ with observable supraorbital regions

Table 1. Antemortem tooth loos (AMTL) of Qau skeletal series in early middle age and late middle age

\begin{tabular}{|c|c|c|c|c|c|c|c|c|c|c|c|}
\hline \multirow[b]{3}{*}{ Male } & \multicolumn{10}{|c|}{ Tooth type } & \multirow[b]{4}{*}{ Grand total } \\
\hline & \multicolumn{5}{|c|}{ Upper } & \multicolumn{5}{|c|}{ Lower } & \\
\hline & & & & & & & & & & & \\
\hline Early middle age & I & $\mathrm{C}$ & $\mathrm{P}$ & M & Total & I & $\mathrm{C}$ & $\mathrm{P}$ & M & Total & \\
\hline Observed & 146 & 73 & 146 & 212 & 577 & 144 & 72 & 144 & 216 & 576 & 1153 \\
\hline Loss & 6 & 1 & 7 & 30 & 44 & 1 & 0 & 5 & 37 & 43 & 87 \\
\hline$\%$ AMTL & 4.11 & 1.37 & 4.79 & 14.15 & 7.63 & 0.69 & 0 & 3.47 & 17.15 & 7.47 & 7.55 \\
\hline \multicolumn{12}{|l|}{ Late middle age } \\
\hline Observed & 76 & 38 & 76 & 114 & 304 & 60 & 30 & 60 & 86 & 236 & 540 \\
\hline Loss & 9 & 3 & 15 & 47 & 74 & 5 & 2 & 8 & 23 & 38 & 76 \\
\hline$\%$ AMTL & 11.84 & 7.90 & 19.74 & 41.23 & 24.34 & 13.64 & 13.64 & 11.63 & 27.69 & 18.39 & 14.07 \\
\hline $\begin{array}{l}\text { Early middle age } \\
\text { vs. Late middle age }\end{array}$ & $\begin{array}{c}P=0.135 \\
\text { ns }\end{array}$ & $\begin{array}{c}P=0.333 \\
\text { ns }\end{array}$ & $\begin{array}{c}P<0.01 \\
\mathrm{~L}>\mathrm{E}\end{array}$ & $\begin{array}{l}P<0.001 \\
\quad \mathrm{~L}>\mathrm{E}\end{array}$ & $\begin{array}{l}P<0.001 \\
\quad \mathrm{~L}>\mathrm{E}\end{array}$ & $\begin{array}{c}P<0.001 \\
\quad \mathrm{~L}>\mathrm{E}\end{array}$ & $\begin{array}{c}P<0.05 \\
\mathrm{~L}>\mathrm{E}\end{array}$ & $\begin{array}{c}P=0.051 \\
\mathrm{~ns}\end{array}$ & $\begin{array}{l}P<0.001 \\
\quad \mathrm{~L}>\mathrm{E}\end{array}$ & $\begin{array}{c}P<0.001 \\
\quad \mathrm{~L}>\mathrm{E}\end{array}$ & $\begin{array}{c}P<0.001 \\
\mathrm{~L}>\mathrm{E}\end{array}$ \\
\hline \multicolumn{12}{|c|}{ Female } \\
\hline Early middle age & I & $\mathrm{C}$ & $\mathrm{P}$ & M & Total & I & $\mathrm{C}$ & $\mathrm{P}$ & M & Total & Grand total \\
\hline Observed & 232 & 115 & 226 & 323 & 896 & 208 & 105 & 212 & 315 & 840 & 1736 \\
\hline Loss & 7 & 4 & 12 & 48 & 71 & 7 & 2 & 12 & 58 & 79 & 150 \\
\hline $\begin{array}{l}\% \text { AMTL } \\
\text { Late middle age }\end{array}$ & 3.02 & 3.48 & 5.31 & 14.86 & 7.92 & 3.37 & 1.90 & 5.66 & 18.41 & 9.40 & 8.64 \\
\hline Observed & 68 & 34 & 68 & 102 & 272 & 57 & 30 & 60 & 87 & 234 & 506 \\
\hline Loss & 9 & 2 & 20 & 59 & 87 & 1 & 1 & 6 & 27 & 35 & 122 \\
\hline$\%$ AMTL & 8.82 & 5.88 & 29.41 & 57.84 & 31.99 & 1.75 & 3.33 & 10.00 & 31.03 & 14.96 & 24.11 \\
\hline $\begin{array}{l}\text { Early middle age } \\
\text { vs. Late middle age }\end{array}$ & $\begin{array}{c}P=0.135 \\
\text { ns }\end{array}$ & $\begin{array}{c}P=0.333 \\
\text { ns }\end{array}$ & $\begin{array}{c}P<0.01 \\
\mathrm{~L}>\mathrm{E}\end{array}$ & $\begin{array}{c}P<0.001 \\
\quad \mathrm{~L}>\mathrm{E}\end{array}$ & $\begin{array}{c}P<0.001 \\
\quad \mathrm{~L}>\mathrm{E}\end{array}$ & $\begin{array}{c}P<0.001 \\
\quad \mathrm{~L}>\mathrm{E}\end{array}$ & $\begin{array}{c}P<0.05 \\
\mathrm{~L}>\mathrm{E}\end{array}$ & $\begin{array}{c}P=0.051 \\
\mathrm{~ns}\end{array}$ & $\begin{array}{c}P<0.001 \\
\quad \mathrm{~L}>\mathrm{E}\end{array}$ & $\begin{array}{c}P<0.001 \\
\quad \mathrm{~L}>\mathrm{E}\end{array}$ & $\begin{array}{c}P<0.001 \\
\quad \mathrm{~L}>\mathrm{E}\end{array}$ \\
\hline
\end{tabular}

I, incisors; C, canines; P, premolars; M, molars in tooth type distribution.

ns, not significant.

E, early middle age; L, late middle age. 
Table 2. Degree of dental wear of Qau skeletal series in early middle age and late middle age

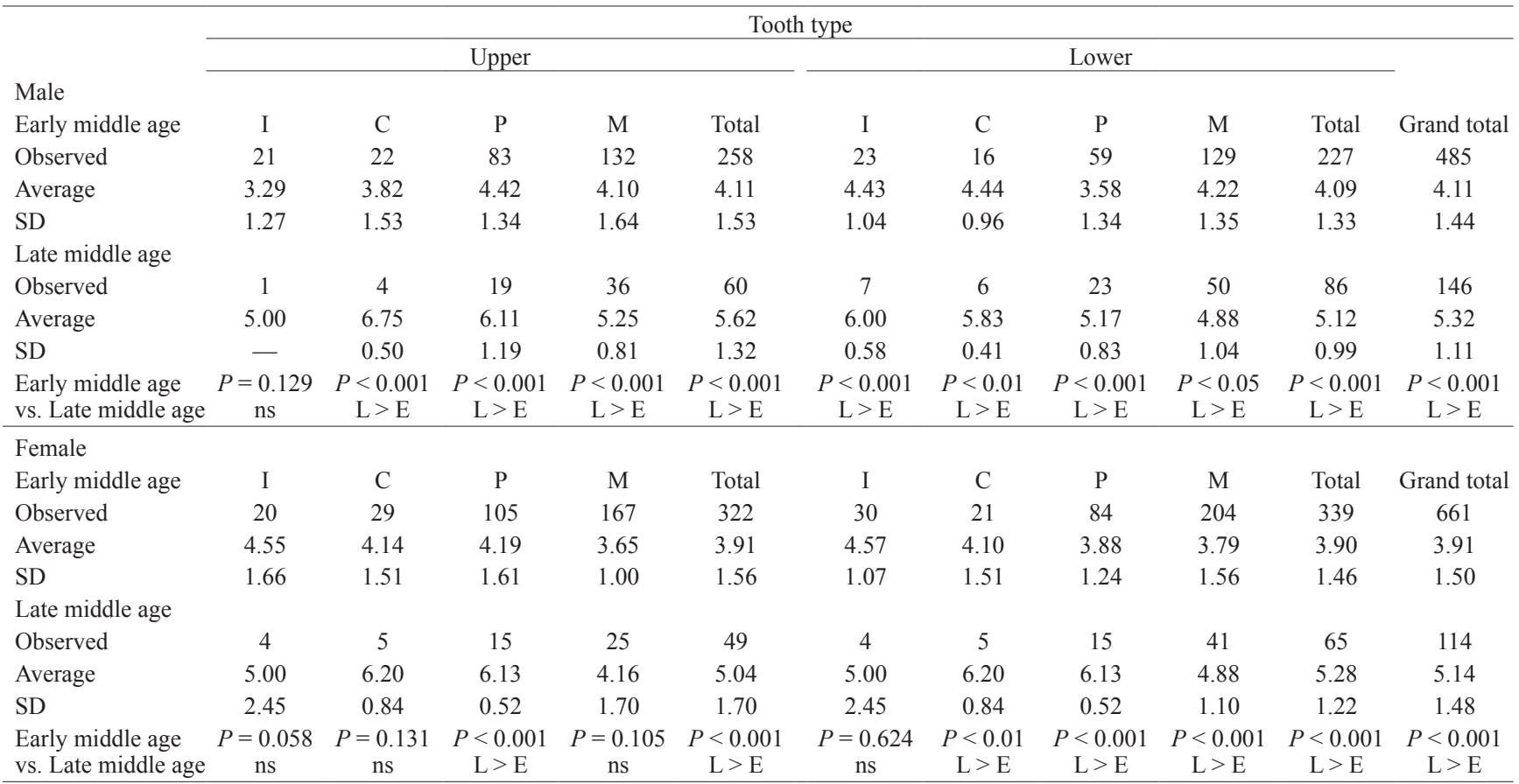

$\mathrm{I}$, incisors; C, canines; P, premolars; $\mathrm{M}$, molars in tooth type distribution.

ns, not significant.

E, early middle age; $\mathrm{L}$, late middle age.

Table 3. Alveolar recession of Qau skeletal series in early middle age and late middle age

\begin{tabular}{|c|c|c|c|c|c|c|c|}
\hline \multirow{3}{*}{ Male } & \multicolumn{6}{|c|}{ Tooth type } & \multirow[b]{4}{*}{ Grand total } \\
\hline & \multicolumn{3}{|c|}{ Upper } & \multicolumn{3}{|c|}{ Lower } & \\
\hline & & & & & & & \\
\hline Early middle age & URM1 & ULM1 & Total & LRM1 & LLM1 & Total & \\
\hline Observed & 28 & 22 & 50 & 24 & 22 & 46 & 96 \\
\hline Average & 4.11 & 3.86 & 4.02 & 3.42 & 3.22 & 3.26 & 3.65 \\
\hline $\mathrm{SD}$ & 0.92 & 0.89 & 0.96 & 1.86 & 1.35 & 1.58 & 1.32 \\
\hline \multicolumn{8}{|l|}{ Late middle age } \\
\hline Observed & 5 & 7 & 12 & 9 & 7 & 16 & 28 \\
\hline Average & 4.00 & 4.71 & 5.08 & 5.00 & 4.57 & 4.81 & 4.82 \\
\hline $\mathrm{SD}$ & 1.00 & 2.06 & 2.02 & 2.29 & 2.64 & 2.37 & 2.04 \\
\hline $\begin{array}{l}\text { Early middle age } \\
\text { vs. Late middle age }\end{array}$ & ns & ns & $\begin{array}{c}P<0.01 \\
\mathrm{~L}>\mathrm{E}\end{array}$ & $\begin{array}{c}P<0.05 \\
\mathrm{~L}>\mathrm{E}\end{array}$ & ns & $\begin{array}{c}P<0.01 \\
\mathrm{~L}>\mathrm{E}\end{array}$ & $\begin{array}{c}P<0.001 \\
\mathrm{~L}>\mathrm{E}\end{array}$ \\
\hline \multicolumn{8}{|l|}{ Female } \\
\hline Early middle age & URM1 & ULM1 & Total & LRM1 & LLM1 & Total & Grand total \\
\hline Observed & 35 & 38 & 73 & 34 & 33 & 67 & 140 \\
\hline Average & 3.66 & 3.58 & 3.65 & 2.82 & 2.77 & 2.80 & 3.22 \\
\hline $\mathrm{SD}$ & 1.57 & 1.50 & 1.50 & 1.64 & 1.38 & 1.51 & 1.06 \\
\hline \multicolumn{8}{|l|}{ Late middle age } \\
\hline Observed & 4 & 2 & 6 & 9 & 3 & 12 & 18 \\
\hline Average & 5.50 & 7.50 & 6.17 & 4.33 & 4.67 & 4.22 & 5.00 \\
\hline $\mathrm{SD}$ & 1.29 & 0.71 & 1.47 & 1.32 & 1.15 & 1.24 & 1.53 \\
\hline $\begin{array}{l}\text { Early middle age } \\
\text { vs. Late middle age }\end{array}$ & $\begin{array}{c}P<0.05 \\
\mathrm{~L}>\mathrm{E}\end{array}$ & $\begin{array}{c}P<0.001 \\
\mathrm{~L}>\mathrm{E}\end{array}$ & $\begin{array}{c}P<0.001 \\
\mathrm{~L}>\mathrm{E}\end{array}$ & $\begin{array}{c}P<0.05 \\
\mathrm{~L}>\mathrm{E}\end{array}$ & $\begin{array}{c}P<0.05 \\
\mathrm{~L}>\mathrm{E}\end{array}$ & $\begin{array}{c}P<0.001 \\
\quad \mathrm{~L}>\mathrm{E}\end{array}$ & $\begin{array}{c}P<0.001 \\
\mathrm{~L}>\mathrm{E}\end{array}$ \\
\hline
\end{tabular}

ns, not significant.

E, early middle age; L, late middle age. 
Table 4. Prevalence of dental caries of Qau skeletal series in early middle age and late middle age

\begin{tabular}{|c|c|c|c|c|c|c|c|c|}
\hline \multicolumn{4}{|c|}{ Male early middle age } & \multicolumn{4}{|c|}{ Male late middle age } & \multirow{2}{*}{$P$-value } \\
\hline Tooth type & Observed & Caries & $\%$ Caries & Tooth type & Observed & Caries & $\%$ Caries & \\
\hline UI & 146 & 0 & 0 & UI & 76 & 0 & 0 & - \\
\hline UC & 73 & 0 & 0 & UC & 38 & 0 & 0 & - \\
\hline UP & 146 & 6 & 4.14 & UP & 76 & 4 & 5.26 & 0.972 \\
\hline UM & 212 & 21 & 9.91 & UM & 114 & 11 & 9.65 & 0.946 \\
\hline U-total & 577 & 27 & 4.68 & U-total & 304 & 15 & 4.93 & 0.872 \\
\hline LI & 144 & 0 & 0 & LI & 60 & 0 & 0 & - \\
\hline $\mathrm{LC}$ & 72 & 0 & 0 & $\mathrm{LC}$ & 30 & 0 & 0 & - \\
\hline LP & 144 & 0 & 0 & LP & 60 & 0 & 0 & - \\
\hline LM & 216 & 12 & 2.05 & $\mathrm{LM}$ & 86 & 2 & 2.33 & 0.728 \\
\hline L-total & 576 & 12 & 2.08 & L-total & 236 & 2 & 0.85 & 0.834 \\
\hline Grand total & 1153 & 39 & 3.38 & Grand total & 540 & 17 & 3.15 & 0.059 \\
\hline \multicolumn{4}{|c|}{ Female early middle age } & \multicolumn{4}{|c|}{ Female late middle age } & \\
\hline Tooth type & Observed & Caries & $\%$ Caries & Tooth type & Observed & Caries & $\%$ Caries & \\
\hline UI & 23 & 1 & 4.35 & UI & 68 & 0 & 0 & 0.584 \\
\hline UC & 115 & 1 & 0.87 & $\mathrm{UC}$ & 34 & 0 & 0 & 0.512 \\
\hline UP & 226 & 3 & 1.33 & UP & 68 & 2 & 2.94 & 0.726 \\
\hline UM & 323 & 30 & 9.29 & UM & 102 & 3 & 2.94 & 0.805 \\
\hline U-total & 687 & 35 & 5.09 & U-total & 272 & 5 & 1.84 & $0.044 *$ \\
\hline LI & 208 & 0 & 0 & LI & 57 & 0 & 0 & - \\
\hline $\mathrm{LC}$ & 105 & 0 & 0 & $\mathrm{LC}$ & 30 & 0 & 0 & - \\
\hline LP & 212 & 1 & 0.47 & LP & 60 & 1 & 1.67 & 0.817 \\
\hline $\mathrm{LM}$ & 315 & 23 & 7.30 & $\mathrm{LM}$ & 87 & 2 & 2.30 & 0.169 \\
\hline L-total & 840 & 24 & 2.86 & L-total & 234 & 3 & 1.28 & 0.273 \\
\hline Grand total & 1527 & 59 & 3.86 & Grand total & 506 & 8 & 1.58 & $0.023 *$ \\
\hline
\end{tabular}

U, upper; L, lower.

$\mathrm{I}$, incisor; C, canine; $\mathrm{P}$, premolar; $\mathrm{M}$, molar.

$* P<0.05$.

Table 5. Site of caries cavities in Qau skeletal series

\begin{tabular}{lccccc}
\hline & Observed $(n)$ & Coronal & Root & Unjudgeable & Significant (C vs. R) \\
\hline Male early middle age & 23 & 4 & 17 & 2 & $P<0.05$ \\
Male late middle age & 10 & 0 & 7 & 3 & $P<0.05$ \\
Female early middle age & 53 & 12 & 38 & 3 & $P<0.01$ \\
Female late middle age & 24 & 4 & 15 & 5 & $\mathrm{~ns}$ \\
Total & 110 & 20 & 77 & 13 & $P<0.001$ \\
\hline
\end{tabular}

C, coronal caries; $\mathrm{R}$, root caries.

ns, not significant.

(Table 7). No significant differences were found in the tests comparing males and females, differences in age, or any combinations thereof.

\section{Discussion}

\section{Periodontal disease and caries}

First, this paper will discuss the two major oral diseases, periodontal disease and dental caries. As shown in Table 1, AMTL in early middle age was $7.55 \%$ in males and $8.64 \%$ in females, which are extremely low values, representing a loss of 2-3 teeth out of 32. In late middle age, AMTL reached $15.02 \%$ in males and $24.11 \%$ in females, which indicates the loss of about 4.8-7.7 teeth. The number of lost teeth clearly increased with age. Whereas Table 3 indicates that in males a significant age-related change in alveolar recession was found, Table 4 shows no age-related change in the rate of caries. In females, however, the rate of dental caries was found to be higher in early middle age than in late middle age. From these findings we can infer that the cause of tooth loss in Qau people differed between males and females. In other words, we can surmise that the primary cause of tooth loss in males was periodontal disease rather than dental caries (Fujita, 2013). On the other hand, although the rate of caries in females is not particularly high, we can probably assume that caries in early middle age was one cause of the high AMTL value in late middle age. This matter will require further study in the future. We found few 
Table 6. LEH of Qau skeletal series in early middle age and late middle age

\begin{tabular}{lrrc}
\hline Enamel hyposplasia & $n$ & Observed (\%) & Significant \\
\hline Age change & & & \\
Male early middle age & 33 & $11(33.33)$ & ns \\
Male late middle age & 15 & $3(20.00)$ & \\
Female early middle age & 47 & $16(34.04)$ & ns \\
Female late middle age & 13 & $4(30.77)$ & \\
\hline Sex difference & & & \\
Male early middle age & 33 & $11(33.33)$ & \multirow{2}{*}{ ns } \\
Female early middle age & 47 & $16(34.04)$ & \\
Male late middle age & 15 & $3(20.00)$ & $\mathrm{ns}$ \\
Female late middle age & 13 & $4(30.77)$ & \\
\hline Total & 108 & $34(31.48)$ & \\
\hline
\end{tabular}

ns, not significant.

Table 7. Cribra orbitalia of Qau skeletal series in early middle age and late middle age

\begin{tabular}{lccc}
\hline Enamel hyposplasia & $n$ & Observed (\%) & Significant \\
\hline Age change & & & \\
Male early middle age & 38 & $10(26.32)$ & ns \\
Male late middle age & 18 & $1(5.56)$ & \\
Female early middle age & 51 & $9(17.65)$ & ns \\
Female late middle age & 17 & $1(5.88)$ & \\
\hline Sex difference & & & \\
Male early middle age & 38 & $10(26.32)$ & ns \\
Female early middle age & 51 & $9(17.65)$ & \\
Male late middle age & 18 & $1(5.56)$ & $\mathrm{ns}$ \\
Female late middle age & 17 & $1(5.58)$ & \\
\hline Total & 124 & $21(16.94)$ & \\
\hline
\end{tabular}

ns, not significant.

anterior caries but a high incidence of posterior caries in both early and late middle-aged males and females. This finding tends to mirror previously reported findings in other populations (Fujita, 1995, 2013).

Although we cannot speculate on the details, based on the roughly $3 \%$ rate of caries in both males and females, it can be assumed that the sugar and carbohydrate intake of the Qau people was low (Fujita, 1995; Keenleyside, 2008), and their eating habits probably did not induce frequent caries. However, a comparison with modern Somalians and Nigerians in the collection at the University of Cambridge revealed that in fact the ancient Egyptians clearly had a higher rate of caries (Fujita, 2013, 2014). In Egyptology, and in anthropology in general, such a finding may become a major topic in future research involving eating habits.

To summarize, Gerloni et al. (2009) reported that X-ray images of mummies revealed pronounced dental wear and periodontal disease, and Melcher et al. (1997) noted that $\mathrm{X}$-ray analysis revealed pronounced dental wear, as well as frequent caries and periodontitis, which agrees with the results of this study. The Qau people appear to have suffered from periodontal disease starting in early middle age; the disease progressed with age and induced alveolar bone recession, and eventually the tooth could not be supported and was lost (as noted above, the issue of caries in females must be examined further). Regarding tooth type, age-related changes, if any, could be seen more clearly in posterior teeth. In the mandible significant age-related changes were also found in anterior teeth, but in the maxilla no clear age-related changes in the anterior teeth were found. The cause of this discrepancy is unclear and is a topic for future study. However, as the first author has verified in people of the Edo period of Japan, the number of remaining teeth in late middle age was much higher than expected, and it is clear that tooth loss was also low in the Qau people as well (Fujita, 2012).

\section{Extent of dental wear}

Regarding dental wear, Table 2 shows that in the anterior region of the maxilla there were tooth types showing no age-related changes, but wear in posterior teeth clearly reflected progression with age. However, wear in the anterior teeth exhibited relatively high values in early middle age, and the anterior teeth might have been used for an activity other than mastication. The first author has studied dental wear in historical samples of both Nigerians and Somalians (Fujita, 2013, 2014) and found that Nigerians had a higher score for dental wear compared to the Somalians. The Nigerians studied lived in the second half of the 19th century, and the Somalians from the end of the 19th century to the beginning of the 20th century, so differences in time, dietary habits, etc., may affect those findings.

\section{Locations of dental caries}

The first author has already published a method for classifying the location of caries (Fujita et al., 1994; Fujita, 2002). In this study, however, the rate of caries was low, about $3 \%$, so a classification method involving two locations, coronal and root, was chosen rather than the more detailed classification. As shown in Table 5, there were significantly more root caries in both males and females starting in early middle age, and although significant differences were found between coronal and root caries in all but late middle-aged females, a large majority of caries that were judged too large to evaluate are believed to have developed from root caries. As the first author has indicated previously (Fujita et al., 1994; Fujita, 2002), if that is the case, the Qau people had frequent root caries, which can be considered a typical caries in ancient peoples (Lunt, 1974; Moore and Corbett, 1971, 1973, 1976; Fujita, 2009; Fujita et al., 2011). The cause can be interpreted as recession of the alveolar bone from periodontal disease and subsequent attack by caries on the root cementum, which is structurally weaker than the enamel. Moreover, it appears that the occlusal surfaces become flat due to pronounced dental wear starting in early middle age, and as a result, carious lesions do not form on the occlusal surfaces.

\section{Linear enamel hypoplasia}

No significant differences based on sex and age were found in the frequency of LEH. Because the enamel is formed in the period from infancy to childhood (Jalevik and Noren, 2000), enamel hypoplasia is unrelated to changes with aging. Moreover, LEH frequencies in both early middle-aged males and females were very similar, and this indicates that even if malnutrition had occurred in infancy, 
the proportion of boys and girls affected by malnutrition was the same (Obertova and Thurzo, 2008). Moreover, LEH frequencies in modern Nigerians and Somalians are either similar to or actually higher than in the Qau people. This matter has implications not only in prehistoric Egyptian anthropology from the standpoint of reconstructing that society, but also from its possible application to public health and welfare administration today in terms of the nutritional status in modern African countries. Based on the frequency of enamel hypoplasia, Starling and Stock (2007) have surmised that the introduction of agriculture improved the nutritional status of people in the Nile valley. Keita and Boyce (2001) also investigated enamel hypoplasia in ancient Egyptians excavated from the Naqada region, and indicated that such a marker correlates with increased population density and social complexity; hence enamel hypoplasia can be interpreted as a stress marker. However, we must often consider 'catchup growth,' an osteological paradox, when we use LEH for the evaluation of paleohealth status. Temple (2008) and Domett and Tayles (2006) indicated that the prevalence of LEH and stature were not correlated in Japanese Jomon peoples and Thailand skeletal remains from the Bronze Age, respectively. The kind of resource materials in this study were not present in that document, and the conditions of the excavation are unclear. Moreover, because of the large difference in time periods, it is hoped that a more detailed investigation will be possible.

\section{Cribra orbitalia}

CO was mostly mild, and the frequency was relatively low at $16.94 \%$ in comparison with that of Dachleh Oasis Egyptians at $75.00 \%$ (Scott and Molto, 2000). This finding should not be interpreted in terms of the Qau people enjoying a good nutritional status but rather that these people died before transitioning to a serious medical condition. This phenomenon is referred to as the osteological paradox or paleopathological paradox (Keenleyside, 1998; Keita and Boyce, 2001; Papathanasiou, 2005; Klaus and Tam, 2009; Redfern and DeWitte, 2011; Turner and Armelagos, 2012). In other words, a society in which many bones and teeth remain from individuals who had a serious disease/condition, be this anemia, malnutrition, or infection, indicates a prosperous society where it was possible to become seriously ill and still survive. Conversely, in a society exposed to severe environmental stress, such individuals died before they became seriously ill, and as a result, the bones and teeth are relatively pristine, and even if there are traces of stress markers, no seriously ill individuals are found. Even physical anthropologists often do not understand this paradox when reconstructing the health status of an ancient society through stress markers, and they tend to make flawed interpretations. In comparing the health status of one population with another, paleopathologists must study this matter carefully and convey their findings clearly to the world.

\section{Concluding remarks}

In this study, a dental paleopathological and paleoepidemiological study, some of the results give the impression that the ancient inhabitants of Qau might have been healthier than modern African Somalians (21.43\% in early middle age and $38.46 \%$ in late middle age, respectively) and Nigerians (21.4\% in age pooled) following the first author's previous studies (Fujita, 2013, 2014). However, we should recall that the reason no bones of juveniles, including infants and newborn babies, were found was because these were so gracile and returned easily to the soil. The reason few elderly bones were found was probably because people did not survive until old age. One way or the other, like most ancient societies, it is easy to imagine that the infant mortality rate in ancient Qau was very high. In the future, we need to consider how to estimate the mortality rate of juveniles, infants and newborn babies who did not leave skeletal remains as this is important for estimating the actual level of their physical health status. Instead of simply using CO and LEH frequencies to compare degrees of health, we should fully consider the osteological paradox, i.e. the fundamental problem that human skeletal remains do not persist for ever, and that high frequencies of stress markers do not always indicate unhealthiness.

\section{Acknowledgments}

The authors thank Dr. M.M. Lahr, Director of the Duckworth Laboratory, Leverhulme Centre for Human Evolutional Studies, University of Cambridge, UK, for her kind permission to study the materials under her care.

\section{References}

Domett K. and Tayles N.G. (2006) Human biology from the Bronze Age to the Iron Age in the Mun River valley of northeast Thailand. In: M. Oxsenham and N.G. Tayles (eds.), Bioarchaeology of Southeast Asia. Cambridge Studies in Biological and Evolutionary Anthropology 43. Cambridge University Press, Cambridge, pp. 220-240.

Forshaw R.J. (2009a) The practice of dentistry in ancient Egypt. British Dental Journal, 206: 481-486.

Forshaw R.J. (2009b) Dental health and disease in ancient Egypt. British Dental Journal, 206: 421-424.

Fujita H. (1993) Degree of dental attrition of the Kanenokuma Yayoi population. Anthropological Science, 101: 291-300.

Fujita H. (1995) Geographical and chronological differences in dental caries in the Neolithic Jomon period of Japan. Anthropological Science, 103: 23-37.

Fujita H. (2002) Historical change of dental carious lesions from prehistoric to modern times in Japan. Japanese Journal of Oral Biology, 44: 87-95.

Fujita H. (2009) Dental caries in Japanese human skeletal remains. Journal of Oral Biosciences, 51: 105-114.

Fujita H. (2012) The number of missing teeth in people of the Edo period in Japan in the 17th to 19th centuries. Gerodontology, 29: $520-524$.

Fujita H. (2013) Dental diseases and stress markers on crania in the early modern people of Nigeria. Japanese Journal of Gerodontology, 28: 10-19.

Fujita H. (2014) Health status in early modern Somali people from their skeletal remains. International Journal of Archaeology, 2: $1-5$.

Fujita H., Suzuki T., Ishiyama N., Hirano H. and Watanabe I. (1994) Distribution of dental caries cavities in the Neolithic Jomon population of Japan. Japanese Journal of Oral Biology, 36: 558-561.

Fujita H., Hashimoto H., Shoda S., and Suzuki T. (2011) Dental caries prevalence as a product of agriculture and subsistence pattern at the Yean-ri site, South Korea. Caries Research, 45: 
524-531.

Gerloni A., Cavalli F., Costantinides F., Costantinides F., Bonetti S., and Paganelli C. (2009) Dental status of three Egyption mummies: radiological investigation by multislice computerized tomography. Oral Surgery, Oral Medicine, Oral Pathology and Oral Radiology Endodontics, 107: e58-64.

Jalevik B. and Noren J. G. (2000) Enamel hypomineralization of permanent first molars: a morphological study and survey of possible aetiological factors. International Journal of Paediatric Dentistry, 10: 278-289.

Keenleyside A. (1998) Skeletal evidence of health and disease in pre-contact Alaskan Eskimos and Aleuts. American Journal of Physical Anthropology, 107: 51-70.

Keenleyside A. (2008) Dental pathology and diet at Apollonia, a Greek colony on the Black Sea. International Journal of Osteoarchaeology, 18: 262-279.

Keita S.O. and Boyce A.J. (2001) Diachronic patterns of dental hypoplasias and vault porosities during the predynastic in the Naqada region, Upper Egypt. American Journal of Human Biology, 13: 733-743.

Klaus H.D. and Tam M.E. (2009) Contact in Andes: bioarchaeology of systemic stress in colonial Mórrope, Peru. American Journal of Physical Anthropology, 138: 356-368.

Leek F.F. (1966) Observations on the dental pathology seen in ancient Egyptian skulls. Journal of Egyptian Archaeology, 52: $59-64$.

Leek F.F. (1967) The practice of dentistry in ancient Egypt. Journal of Egyptian Archaeology, 53: 51-58.

Leek F.F. (1972a) Teeth and bread in ancient Egypt. Journal of Egyptian Archaeology, 58: 126-132.

Leek F.F. (1972b) Bite, attrition and associated oral conditions as seen in ancient Egyptian skull. Journal of Human Evolution, 1: 289-295.

Leek F.F. (1973) Further studies concerning ancient Egyptian bread. Journal of Egyptian Archaeology, 59: 199-204.

Lunt D.A. (1974) The prevalence of dental caries in the permanent dentition of Scottish prehistoric and mediaeval populations. Archives of Oral Biology, 19: 431-437.

Matsumoto H. (1995) Maxillofacial and Oral Surgery, 1st edn. Oral Health Association of Japan, Tokyo.

Meindl R.S. and Lovejoy C.O. (1985) Ectocranial suture closure: a revised method for the determination of skeletal age at death based on the lateral-anterior sutures. American Journal of Physical Anthropology, 68: 57-66.

Melcher A.H., Holowka S., Pharoah M., and Lewin P.K. (1997) Non-invasive computed tomography and three-dimensional reconstruction of the dentition of a 2800-year-old Egyptian mummy exhibiting extensive dental disease. American Journal of Physical Anthropology, 103: 329-240.

Moore W.J. and Corbett M.E. (1971) The distribution of dental caries in ancient British populations. I. Anglo-Saxon period. Caries Research, 5: 151-168.

Moore W.J. and Corbett M.E. (1973) The distribution of dental caries in ancient British populations. II. Iron Age, RomanoBritish and mediaeval periods. Caries Research, 7: 139-153.

Moore W.J. and Corbett M.E. (1976) Distribution of dental caries in ancient British populations. IV. The 19th century. Caries Research, 10: 401-414.

Nathan H. and Hass N. (1966) On the presence of cribra orbitalia in apes and monkeys. American Journal of Physical Anthropology, 24: 351-360.

Obertova Z. and Thurzo M. (2008) Relationship between cribra orbitalia and enamel hypoplasia in the early medieval Slavic population at Borovce, Slovakia, International Journal of Osteoarchaeology, 18: 280-292.

Papathanasiou A. (2005) Health status of the Neolithic population of Alepotrypa Cave, Greece. American Journal of Physical Anthropology, 126: 377-390.

Redfern R.C. and DeWitte S.N. (2011) A new approach to the study of Romanization in Britain: a regional perspective of cultural change in late Iron Age and Roman Dorset using the Siler and Gompertz-Makeham models of mortality. American Journal of Physical Anthropology, 144: 269-285.

Scott I.F. and Molto J.E. (2000) Cribra orbitalia in two temporally disjunct population samples from the Dakhleh Oasis, Egypt. American Journal of Physical Anthropology, 111: 319-331.

Starling A.P. and Stock J.T. (2007) Dental indicators of health and stress in early Egyptian and Nubian agriculturalists: a difficult transition and gradual recovery. American Journal of Physical Anthropology, 134: 520-528.

Temple D.H. (2008) What can variation in stature reveal about environmental differences between prehistoric Jomon foragers? Understanding the impact of systemic stress on developmental stability. American Journal of Human Biology, 20: 431439.

Turner B.L. and Armelagos G.J. (2012) Diet, residential origin, and pathology at Machu Picchu, Peru. American Journal of Physical Anthropology, 149: 71-83.

Yamamoto M. (1989) Enamel hypoplasia in deciduous teeth of Edo Japanese. Journal of the Anthropological Society of Nippon, 97: 475-482. 